И. А. Есаулов

Москва

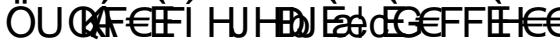

\section{ЕВАНГЕЛЬСКИЙ ТЕКСТ В РУССКОЙ КУЛЬТУРЕ И СОВРЕМЕННАЯ НАУКА}

искуссии по поводу корректности тех новых подходов, которые предлагаются для изучения отечественной литературы в пяти выпусках "Евангельского текста...», являются живым свидетельством развития, а не стагнащии этого направления в отечественной филологии. Стремление же во что бы то ни стало дискредитировать саму тему обсуждения, преуменьшить ее значение для истории нашей словесности говорит о том, что теми, кто десятилетиями пытался препятствовать развитию русской гуманитарной науки в этой важнейшей для русской духовности сдрере, здесь опознается опасность для собственного монопольного, как это было ранее, положения. Что эти силы могут противопоставить законному стремлению рассматривать русскую литературу в контексте русской христианской культуры? В сущности, ничего, кроме попыток личной дискредитации, ничего, кроме не удавшегося замалчивания, и ничего, кроме унаследованной от советского времени недобросовестной подковерной борьбы. На собственно же научном поле, там, где ведется открытая научная дискуссия, а не закулисный сговор, невозможно отрицать значимость для русской фрилологической науки академического изучения евангельского текста.

(С) Есаулов И. А., 2011
Но с какими критериями и с каким инструментарием подходить к этому предмету?

В современных гуманитарных дисциплинах можно выделить два принципиально различных подхода к своему объекту: как к внешнему для самого исследователя предмету, предполагающему то или иное объяснение, и как к объекту, требующему внутреннего понимания.

«Изучение» отнюдь не является синонимом «понимания». Если «изучение» возможно как в гуманитарных науках, так и в негуманитарных, то понилание является прерогативой «наук о духе», как назвал когда-то нашу сферу интересов Вильгельм Дильтей. Понимание же, в отличие от внешнего «изучения», предполагает известное личностное созвучие между предметом понимания и его истолкователем. Подлинного понимания нет там, где нет любви. Это относится не только к фрилологии, но именно фрилология наука, предполагавшая в самой своей колыбели любовное отношение к своему предмету: фрило-логия. Ясно, например, что письмо Белинского к Гоголю предполагает что угодно, только не подлинное понимание духовного вектора творчества Гоголя. Напротив, это письмо задает совершенно противоположную перспективу: непонилания Гоголя. К сожалению, именно этот вектор непонилания Гоголя стал основой для его последующего изучения (именно изучения) в нашей стране. Поэтому интерпретащии гоголевских текстов, заданные этим вектором непонилания, не способны обогатить наше представление о Гоголе, они способны обеднить это представление, а также исказить сам предмет рассмотрения.

Не требует особых доказательств, что советское литературоведение с удовольствием подхватило и вульгаризировало революционно-демократическую мифологию в истолковании русской литературы. По-видимому, за современным развертыванием этой же мифологии стоят более глобальные, по преимуществу атеистически ориентированные прогрессистские представления о путях «развития» как общества, так и литературы. Эти представления, приводящие к стремлению унифбииировать и, тем самым, как бы подчинить единой схеме всю историю человечества (марксистские, глобалистские либо какие-то иные), строго говоря, не- 
доказуемы, однако именно поэтому и являются очень существенной частью интеллектуальной мифологии - c ее явной склонностью к «левизне».

Наследующие этой мифологии постсоветские ученые собственный мифб пытаются позицировать в качестве основания гуманитарной науки, считая себя при этом представителяли науки как таковой. Однако описываемая («относительная», по определению А. Ф. Лосева ${ }^{1}$ ) мифология должна знать свое место. В понимании русской литературы это место весьма скромное, лишь по известным историческим и общественным причинам (и по академической инерции) подобный подход к нашей словесности, к сожалению, все еще доминирует в отечественной фрилологии и истории.

Является ли временна́я граница между нами, нынешними исследователями, и русскими писателями препятствием к пониманию? На этот счет возможны различные мнения. Согласно одному из них, конечно, является. Так, например, считал М. Л. Гаспаров, полагая, что научная точка зрения может быть только одна - «историческая». Согласно его установке, «диалог с прошлым оказывается прикрытием экспроприации прошлого; диалог этот мнимый, потому что односторонний: прошлое молчит» ${ }^{2}$. С нашей же точки зрения, «молчит» только безгласная вещь, но не «прошлое». Прошлое как раз «говорит» - в нас и через нас. Хотя, возможно, не всем бы хотелось, чтобы «культурная память» в России обрела, говоря по-бахтински, «свой праздник воскресения» - после советского и постсоветского погрома и осознала бы, наконец, саму себя.

Как полагает Гаспаров, изучая Пушкина, «мы стараемся реконструировать художественное восприятие читателей пушкинского времени только потому, что именно для этих читателей писал Пушкин. Нас он не предугадывал и предугадывать не мог» ${ }^{3}$. Нам же представляется, что са-

\footnotetext{
${ }^{1}$ См.: Лосев А. Ф. Диалектика мифа. М., 2001.

${ }^{2}$ Гаспаров М.Л. История литературы как творчество и исследование: случай Бахтина // Русская литература XX-XXI веков: Проблемы теории и методологии изучения. М., 2002. С. 10

${ }^{3}$ Он же. Предисловие // Ю. М. Лотман и тартуско-московская семиотическая школа. М., 1994. С. $14-15$.
}

мо предположение Гаспарова, согласно которому «именно для читателей пушкинского времени», мол, «писал Пушкин», является отнюдь не «объективно-научным», а уже достаточно произвольным. Хотя бы потому, что у позднего Пушкина с этими самыми «читателями пушкинского времени» были значительные проблемы, как мы все знаем. Но главное состоит в другом. Мы видим в этой установке приверженца «объективной» и «исторической» точки зрения как раз полнейшее неприятие далекого контекста понимания произведения. Представляется, что научное прочтение изучаемого текста именно и только на фоне читательских ожиданий современников автора все-таки нельзя считать единственно правильной гуманитарной установкой.

Начнем с того, что эта установка абсолютно нереализуема: если мы даже очень захотим - как исследователи так сказать, «превратиться» в современников Пушкина, чтобы «прочесть» его произведения на фроне «ожиданий» этих современников, мы, при всем нашем желании, не сможем этого сделать. Мы не сможем так «очиститься» от нашего читательского опыта, чтобы «забыть» о тех эпохах, которые мы в своем культурном опыте уже безвозвратно вобрали в свое сознание. И никакое «специальное фрилологическое образование» ${ }^{4}$ здесь не поможет.

Более того, если бы - каким-то невероятным образом мы и смогли «вернуться» в пушкинскую эпоху, так сказать, вжиться в сознание пушкинских читателей того времени, это содействовало бы не «чистоте» нашего литературоведческого анализа, а, напротив, воспрепятствовало бы истинному, глубокому пониманию Пушкина. В той исторической дистанщии, которая отделяет нас от пушкинской эпохи, имеются, на наш взгляд, и свои позитивные - для понимания этой эпохи - моменты.

В частности, после сокрушения православной России и последовавшего за этим системного искоренения русской христианской культуры мы гораздо отчетливее осознаем значение этой культуры для русской словесности, нежели это осознавали люди, для которых христианская культура была цивилизационной грибницей для самого их бытия;

${ }^{4}$ Там же. С. 14. 
гораздо отчетливее, чем это осознавали, например, современники Пушкина.

Обогащенные новым (пусть и трагическим) контекстом понимания, мы уже не имеем нравственного права с той же легкостью, как наши предшественники, противопоставлять «народное» Православие Православию «догматическому» (точно так же, как и некритически превозносить, скажем, едва ли не все гипотезы отечественного «религиозного ренессанса»); мы должны вначале попытаться описать общий зналенатель, конституирующий единство русской культуры.

Русская Катастрофра XX века вынуждает нас пересмотреть словно бы навсегда в гуманитарных науках определившуюся иерархию "прогрессивных» и "реакционных» литераторов и историков - и совсем не для того, чтобы неизвестно ради какой цели «поменять знаки», а убедившись в постоянной закрепленности самой логикой «левого мифра» почетного титула «прогрессивности» как раз за теми, для кого православный строй Российской империи был тягостной и непереносимой обузой и кто затем в стихах и в прозе восславил, а также "научно обосновал» необходимость насильственного слома всех основ прежней жизни другим подавляемому большинству жителей нашей страны. Мы не должны забывать и о том, что периодами реакиии открыто обозначались периоды государственной стабильности России, а реакиионерали - деятели масштаба И. В. Киреевского и А. С. Хомякова, поскольку они (удачно или неудачно) пытались - каждый по-своему - именно сохранить православную Россию.

Для гаспаровского подхода желаемый итог - как можно более «точное» описание коммуникации между автором и читателем, причем читателем-современником автора стало быть, в пределе, единичной коммуникации. В сущности, понятие «читателя» в данном случае вообще избыточно, потому что ученый убежден в том, что исследователь его ориентации выявляет именно авторскую установку. Поэтому любые уклонения от этой предполагаемой, идеальной в своем пределе коммуникации не что иное, как ошибки, неправильные толкования, ненаучные интерпретации, деконструктивистские подходы и т. п.
На самом же деле декларируемая установка для современной гуманитарной науки является явным анахронизмом. Она приводит не к смиренному отказу от своего исследовательского «я» в пользу автора, a, напротив, к принципиальному исследовательскому монологизму. Как вполне определенно высказался Бахтин: «...в структурализме только один субъект - субъект самого исследователя» ${ }^{5}$ Однако, в отличие от приверженцев постструктурализма, этот «субъект» далеко не всегда отягчен теоретической исследовательской рефлексией, а потому и несколько наивно склонен именовать свой собственный подход к литературе «объективным» и «научным», а иные подходы — «произвольными» или даже «антинаучными».

Иную научную установку актуализирует «далекий» контекст понимания. В нашем литературоведении он связан с именем Бахтина. Согласно этому подходу, великие литературные произведения «разбивают грани своего времени», они «как бы перерастают то, чем они были в эпоху своего создания». В процессе «своей посмертной жизни», как выражается Бахтин, произведения «обогащаются новыми значениями, новыми смыслами». По Бахтину, «автор - пленник своей эпохи, своей современности. Последующие времена освобождают его от этого плена, и литературоведение призвано помочь этому освобождению». Поэтому «творческое понимание не отказывается от себя, от своего места во времени» ${ }^{6}$. Иными словами, Пушкин писал совсем не всегда только для своих современников и даже, может быть, совсем не для своих современников. Его произведения распахнуты в незавершимое «большое время», где исследователь позднейших эпох — как читатель - имеет собственный контекст понимания, и он вовсе не обязан «совпадать» с пониманием пушкинских современников.

Изучение «малого времени» тех или иных литературных событий является только лишь однил из возложных контекстов понимания, к тому же не самого глубокого понимания. Упорствующие в таком подходе к литературе как единственно научном и настаивающие на "историзме» та-

\footnotetext{
${ }^{5}$ Бахтин М. М. Эстетика словесного творчества. М., 1979. С. 372

${ }^{6}$ Там же. С. $331-334$.
} 
кого подхода на самом деле лишь «замыкаются в эпохе» создания произведений. В сущности, эта позиция вообще имеет дело не с пониланием, а с изучениел, совершенно подобным изучению негуманитарного предмета: мертвой, безголосой и (главное) всегда равной самой себе вещи.

«Далекий» же контекст понимания разомкнут во времени. В «большом времени» происходит обновление прежних смыслов. Так, согласно этой установке, «ни сам Шекспир, ни его современники не знали того “великого Шекспира", которого мы теперь знаем». Речь идет о каких-то «новых смысловых глубинах» произведений, а не о «расширении наших фрактических, материальных знаний о них... добываемых археологическими раскопками, открытиями новых текстов, усовершенствованием их расшифровки и т. п.»7. Речь идет о том, что полнота смыслового явления раскрывается только в «большом времени».

Итак, согласно этой второй установке, литературоведение призвано не только копошиться в «малом времени» авторской современности, но, напротив, «призвано помочь... освобождению» ${ }^{8}$ автора от смертных оков этого самого "малого времени». Представляется, что это очень интересно сорормулированная, даже захватывающая цель для нашей филологической науки.

Будучи в целом солидарны с подобной гуманитарной установкой, на протяжении последних десятилетий мы пытались обосновать необходимость выделения еще одного принципа понимания художественного текста, который не сводится ни к «малому времени» создания и восприятия произведений, ни к принципиально незавершимому «большому времени» человеческой культуры как таковой. В свое время М. Вебер провел классическое разграничение между протестантским образом мира и католическим в работе «Протестантская этика и дух капитализма». Для нас в данном случае убедительны не социологические постулаты Вебера, а разграничение больших ментальностей, имеющих свои собственные культурные закономерности; оно не сводится к чисто национальному разграничению, посколь-

\footnotetext{
7 Там же. С. $331,334$.

${ }^{8}$ Там же. C. 332 .
}

ку базируется на более общих сакральных моделях и установках. Позже Р. Пиккио пришел к выводу, что славянские культуры и славянские литературы в своих ментальностях основываются на том, к какому духовному полю тяготеют. Есть «Slavia Romana», а есть «Slavia Orthodoxa» ${ }^{9}$. Русская, белорусская, украинская, болгарская, сербская культуры относятся к «Slavia Orthodoxa», сама их корневая система вырастает из византийского поля православной кирилло-мефодиевской традиции. Значит, добавим мы, она вполне может быть корректно истолкована в категориях этой традиции, таких как соборность, пасхальность, христоцентризл, закон, благодать. Мы попытались истолковать магистральный вектор развития русской словесности и описать классические произведения отечественной литературы в контексте православного типа культуры, опираясь на новые принципы понимания художественного текста ${ }^{10}$.

Следует при этом методологически отчетливо уяснить невозможность существования абстрактной духовности и абстрактной же религиозности. Лукавое словосочетание «религиозная фрилология» лишь затушевывает в данном случае подлинную остроту проблемы. Не только потому, что тогда нужно выделять и особую «атеистическую» филологию, но и потому, что говорить об абстрактной религиозности, так сказать, религиозности вообще, - это даже не «вчерашний», а, так сказать, «позавчерашний» день науки.

Лишь для атеистически ориентированного сознания вполне достаточно противопоставить «материализм» и «религиозность» (скажем, назвав человека «верующим»). Но религиозность всегда бывает той или иной. В свое время мы попытались обосновать необходимость различения типов религиозности при филологическом анализе художественных произведений. Следует, по-видимому, нашему литературоведению различать и типы духовности. Необходимо учиться различению духов: хотя бы для того, чтобы «духов злобы поднебесной» (Еф. 6:12) ненароком не перепутать с иными духами. Речь идет о различных munax ду-

${ }^{9}$ См.: Пиккио P. Slavia Orthodoxa: Литература и язык. М., 2003.

${ }^{10}$ См.: Есаулов И. А. Категория соборности в русской литературе. Петрозаводск, 1995; Он же. Пасхальность русской словесности. М., 2004 . 
ховности, и эти типы духовности имеют свои собственные, далеко не совпадающие представления о «должном» и «недолжном», разные аксиологические акценты.

К сожалению, задача усложняется тем, что весьма часто система ценностей исследователей русской литературы находится в кардинальном противоречии с аксиологией предмета изучения. Причем было бы значительным упрощением говорить о том, что русская классика имеет духовный потенциал, а ее исследователи - бездуховны. Нет, настоящая проблема в том, что зачастую mun духовностu этих исследователей — один, а mun духовности русской литературы - совсем другой. И сама по себе такая ситуация является вполне нормальной. Но иногда - вольно или невольно - происходит проецирование своей собственной системы ценностей, своих собственных представлений о «должном» и «недолжном» на русскую классическую литературу, которая основывается на других ценностях. Тем самым искажается (вольно или невольно) сам предмет исследования. Как правило, это происходит именно в том случае, если православная культурная традиция представляется исследователю русской словесности либо чем-то «недолжным», либо таким «довеском» к литературе, которым можно, с его точки зрения, и пренебречь.

Представляется, что рассмотрение литературного произведения в контексте христианской традиции как особого рода трансисторической длительности вполне отвечает задачам новой исторической поэтики и, во всяком случае, находится в русле размышлений как Веселовского, так и Бахтина. Конечно, это не означает, что следует рабски идти по стопам того же Бахтина. Новое время научило нас отличать «традиционализм» от «традиции», а модернисты Элиот и Мандельштам научили не слишком-то увлекаться «буквой» — в ущерб «духу».

Возникнув в качестве авторских, новые категории фрилологического анализа, упомянутые нами выше, правомерность введения которых, надо сказать, разделяется далеко не всеми, тем не менее вошли в широкий научный и общественный оборот, что доказывается закреплением их в литературных словарях и энциклопедиях. Например, слово «христоцентризм» уже существовало, но сейчас оно конституируется как терлин, вошло в различные словари (в том числе, иноязычные $\left.{ }^{11}\right)$, употребляется в ряде диссертационных исследований в России. То же можно сказать и о других перечисленных выше категориях.

По-видимому, корректировка существующего категориального аппарата литературоведения, обращенного к русской литературе, - действительно насущная необходимость В. Н. Захаров вводит понятие «умиления» - и именно как категорию поэтики Достоевского ${ }^{12}$. В. Лепахин справедливо настаивает на необходимости понятия «иконичности» не в расширительном, а в специальном смысле этого слова $^{13}$. Вспомним и нашу работу, где речь идет о законе и благодати ${ }^{14}$. Можно было бы приводить и другие примеры, свидетельствующие об актуальности подобного подхода в русской фрилологии.

Следует подчеркнуть, что эти новые категории фрилологического анализа имеют не только присущий им объем содержания, но также и свою историю. Можно поэтому говорить не только о следовании христианской традиции, но и о ее трансрормации, о метаморфозах и псевдоморфозах, которые происходят с этой традицией.

В этой связи представляется правильным ввести понятие «вторичная сакрализация», чтобы то "передрорматирование» традиции, которое происходило в советский период, обозначить отдельным специальным термином ${ }^{15}$. В рамках этой вторичной сакрализации происходит, например, подмена соборности, которая утверждает «Ты еси», коллективизмом, базирующимся на совершенно иных принципах.

${ }^{11}$ См., например: Христоцентризм // Идеи в России: Leksykon rosyjsko-polsko-angielski. T. 2. Lodz, 1999. P. 380-382.

12 Захаров В. Умиление как категория поэтики Достоевского // Celebrating Creativity: essays in honour of Jostein Botrnes. Bergen, 1997. P. 237-255.

${ }^{13}$ Лепахин В. Летопись как икона всемирной истории (по «Повести временных лет») // Вестник русского христианского движения. Париж, 1995. № 171. C. 30-42.

${ }^{14}$ Esaulov I. The categories of Law and Grace in Dostoevsky's poetics // Dostoevsky and the Christian Tradition. Cambridge, 2001. P. 116-133.

${ }^{15}$ Подробнее см.: Есаулов И. А. Мистика в русской литературе советского периода: Блок, Горький, Есенин, Пастернак. Тверь, 2002. 
Еще Вяч. Иванов совершенно определенно разграничил два противоположных типа человеческой общности, художественно раскрытые в свое время Достоевским: легион и соборность. Если нехристианский, а затем и открыто антихристианский «легион» предполагает «скопление людей в единство посредством их обезличивания», то «соборность» есть «такое соединение, где соединяющиеся личности достигают совершенного раскрытия и определения своей единственной, неповторимой и самобытной сущности, своей целокупной творческой свободы» ${ }^{16}$. Искажение русской картины мира в изучении нашей литературы проистекало как раз во многом оттого, что «легионеры» и получили в свое время монопольное право на толкование отечественной словесности.

По мысли Вяч. Иванова, находящегося в то время всецело в русле православной традиции, «признание святости за высшую ценность - основа народного миросозерцания и знамя тоски народной по Руси святой. Православие и есть соборование со святынею и соборность вокруг святых» ${ }^{17}$. Беда советской фрилологии состояла в том, что именно эту «высшую ценность» десятилетиями при рассмотрении русской словесности выносили «за скобки» исследовательского внимания, подменяя ее произвольными и внешними по отношению к русскому национальному образу мира категориями и понятиями.

Несколько перефразируя известное высказывание Бахтина из книги о Рабле, эти новые категории позволяют осмыслить русскую литературу как часть русской культуры, где эта литература «оказывается у себя дома»18. Во всяком случае, довольно трудно аргументировать, что эти категории не репрезентативны для христианской культуры: напротив, представляется, что данный инструментарий может быть в большей степени имманентен русской литературе, чем многие другие.

$\mathrm{K}$ изучению евангельского текста можно подходить с позиции, внутренне причастной к евангельским ценностям,

${ }^{16}$ Иванов В. И. Родное и вселенское. М., 1994. С. 100.

17 Там же. С. 335.

${ }^{18}$ Бахтин М. М. Творчество Франсуа Рабле и народная культура Средневековья и Ренессанса. М., 1990. С. 7. однако горькое преимущество нашей нынешней позиции состоит в том, что мы прекрасно знаем: этот же текст весьма часто рассматривали и рассматривают с ярко выраженных антихристианских установок, лишь маскируя их в наше время под «объективно научные».

Ясно, что, если события земной жизни Христа рассматривать с апостольских позиций, они предстают в одном свете, а если те же события рассматривать с точки зрения законников и фрарисеев, то они видятся совершенно иначе. Ясно также, что никакого «примирения» тех и других ожидать не приходится. Не нужно себя обманывать: так сказать, равноудаленной позищии между двумя обозначенными также не существует.

Естественно предположить, что научное описание культурной системы с исследовательской позиции, иманнентной ценностям самой этой культурной системы, резко отличается от описания той же самой системы с совершенно внешних этой системе позиций. Так и происходит с изучением евангельского текста. Однако насколько научно корректной является установка исследователя, комплиментарная ценностям описываемой им системы? Имеются ли какие-либо современные гуманитарные аналоги, помимо фрилологии, которые могли бы дополнительно обосновать научную продуктивность подобной установки? Итак, «научно» ли русскую культуру изучать с позищий эмпатии к русской же культуре и ее доминантным ценностям, к каким, безусловно, относится православная традиция? Возможна ли она в современных гуманитарных дисциплинах? В чем научное преимущество именно такой исследовательской позиции сравнительно с другими?

В методологических постулатах и теоретических установках современных кросс-культурных исследований различаются еmic- и etic-подходы. Эти термины, которые выдвинул К. Л. Пайк по аналогии с фронетикой и фронематикой ${ }^{19}$, были затем поддержаны и разработаны Г. Триандесом ${ }^{20}$. Если фонетика связана с изучением общих аспек-

${ }^{19}$ Cм.: Pike K. L. Language in relation to a unified theory of the structure of human behavior. The Hague: Mouton, 1967. 1980 .
${ }^{20}$ Cm.: Triandis H. C. Handbook of cross-cultural psychology. Boston, 
тов звуков и произнесения звуков, то фронемика - это изучение звуков, используемых в определенном языке.

При етіс-подходе делается попытка рассмотреть явления и их взаимосвязь (структуру) глазами людей, которые относятся к данной культуре. Эта точка зрения берет начало из культурной антропологии, где с помощью метода включенного наблюдения исследователь пытается рассматривать нормы, ценности, мотивы и обычаи членов определенной общности с их собственной точки зрения.

Исследователи, придерживающиеся етіс-подхода, утверждают, что ранее в гуманитарных дисциплинах (например, в психологии) всецело господствовал еtic-подход, который основывался на некритическом проецировании западных гуманитарных установок на внеположный Западу «мир большинства», как они его называют ${ }^{21}$. Таким образом, исследователь той или иной культуры работал на самом деле не с ценностями изучаемой культуры, а с «навязанными этиками» или «псевдоэтиками».

Если попытаться структурировать разницу между этими двумя подходами, разумеется, в нашей собственной интерпретации, то получается такая картина.

1. При еtic-подходе система изучается с какой-либо позиции вне этой системы (марксизм, фрейдизм, структурализм и проч.). Emic-подход позволяет изучать поведение системы изнутри.

2. При еtic-подходе система конструируется аналитиком. При етіс-подходе структура обнаруживается аналитиком, а не конструируется.

3. При еtic-подходе критерии считаются абсолютными или универсальными. При етіс-подходе критерии связаны с внутренними характеристиками.

Также в современных кросс-культурных исследованиях выделяются три ориентации: абсолютистская, универсалистская и релятивистская. Абсолютистская установка предполагает в качестве методов оценки культурной системы стандартный инструментарий, общий для всех типов культур; универсалистская - научный инструментарий, адаптиро-

${ }^{21}$ Cм.: Kagitcibasi C. Family and human development across cultures: A view from the other side. Hillsdale, 1996. ванный к изучаемой культуре; релятивистская же ориентация предполагает создание инструментария, присущего той или иной культуре.

Особенности марксистского метода состояли с том, что он навязывал в той системе координат, о которой мы сейчас рассуждаем, еtic-подход наряду с абсолютистской ориентацией. Не менее существенна при попытке понять адекватность/неадекватность подобного подхода степень искажения объясняемого предмета. Если изучаемая культура базируется на близких самому Марксу ориентирах, она менее искажается вследствие его объяснения. Если она базируется на иных ориентирах, она искажается в большей степени. Если же, как это происходило с Россией, русские ориентиры и марксистские ценности не просто различны, но и противоположно направлены, то в таком случае конечным результатом вполне академического «описания» русской культуры, по Марксу, может быть именно и только деструкция всего русского мира, его передорматирование, согласно совершенно чуждым ему критериям, вплоть до совершенного его уничтожения.

Если мы рассмотрим под подобным же углом зрения упоминавшуюся выше социологическую теорию М. Вебера, которая связывает этику протестантизма с экономическим ростом (некоторую корректировку подобного подхода можно заметить у В. Зомбарта, напрямую соединяющего развитие капитализма с возрастанием роли секулярного иудаизма в современном мире ${ }^{22}$ ), то станет совершенно ясно, что подобные теории претендуют если не на абсолютизм, то на универсализм, хотя эта претензия вряд ли состоятельна. Ведь для «мира большинства» отношения между религией и экономикой иные, нежели в протестантизме и иудаизме. Например, как показывает индийский ученый Д. Сингх, западные модели развития укоренились в западных ценностях, где индивид был и является действующим лицом, а также объектом социального изменения ${ }^{23}$. C западной точки зрения этот индивид относительно незави-

\footnotetext{
${ }^{22}$ Cм.: Золбарт B. Собр. соч.: В 3 т. Т. 3. СПб., 2005. С. 105-643.
${ }^{23}$ Cм.: Singh A. K. Hindu culture and economic development in India // Conspectus. 1967. № 1. P. 9-32.
} 
сим от родительского авторитета, связан со временем и планированием. Он желает отложить удовольствие, предполагает господство над природой, верит в детерминизм и науку, обладает космополитическими взглядами и конкурирует, испытывая удовольствие от превосходства в конкуренции ${ }^{24}$. Но существует (например, в индуизме) и альтернативный психологический профиль личности, когда поведение строится не на соревновании, а на сотрудничестве $^{25}$. Очевидно, православная культура давно выработала свой собственныцй профиль личности, игнорировать и изменять который можно только лишь путем подавления поведенческих стереотипов носителей этой культуры. Именно это насильственное подавление носителей русской православной культуры после сокрушения Российской империи и являлось доминантой советской «культурной револющии».

К сожалению, западные ученые, занимающиеся кросскультурными исследованиями, не знакомы с научным наследием М. М. Бахтина (об этом выразительно свидетельствует их библиография). Согласно его концепции, объяснение всегда тяготеет к «овеществлению» своего объекта (будь то человек или текст), тогда как главный момент гуманитарного понимания - осознание того, что ученый (будь он фрилософ, историк, этнолог, психолог или фрилолог) в акте познания имеет дело с неисчерпаемой личностью, которая до конца никогда не может быть «объяснена». Всякая претензия на сколько-нибудь полное и адекватное «объяснение» в этой области всегда является более или менее научной иллюзией (осознают ли это сами ученые, либо не осознают, настаивая, например, на "комплексности» своего подхода, на необходимости применения нескольких взаимодополнительных методик исследования и т. п.). C этой точки зрения, в еtic-подходе доминирует именно «объяснение», тогда как етіс-подход базируется на «понимании». Евангельский текст именно такой неисчерпаемый предмет понимания, который всегда будет сопротивляться любому внешнему объяснению.

${ }^{24} \mathrm{Cm}$. Triandis H. C. Toward a psychological theory of economic growth // International Journal of Psychology. 1984. № 19. P. 79-95.

${ }^{25}$ Cm.: Sinha D. Psychology in the context of Third World development // International Journal of Psychology. 1980. № 19. P. 17-29.
По многим, не только объективным, но и личностным причинам православные ценности, которые концентрируются в евангельском тексте и православном предании, просто не могли стать предметом сочувственного «понимания» в нашей гуманитарной науке - хотя бы в качестве чуждbıx, если не сказать, чужих. Предметом же внешнего «объяснения» (и разоблачения) они становились, напротив, весьма и весьма часто.

Однако при овнешнении этого особого предмета (евангельского текста) он неизбежно теряет свою собственно новозаветную сакральную специфоку и - при таком подходе - ничем не отличается от любого другого текста. Тем самым происходит подмена самого предмета рассмотрения Например, неточность цитирования автором (или героем) евангельского текста вовсе не всегда непременно свидетельствует о каком-то сознательном его искажении, но может говорить и о той или иной степени адаптации, усвоения и понимания. Кроме того, в русской православной традиции евангельский текст - это не столько книга, лежащая на столе, ее индивидуальное чтение и проекция этого чтения на другие сореры культурной жизни. Это, прежде всего, звучащее Слово в Богослужении и последующая культурная рецепция именно этого звучащего Слова.

Так, насколько можно судить, в современной постсоветской медиевистике возобладал подход А. А. Алексеева, согласно которому сама идея национальной или народной Библии в русской православной традиции является научно непродуктивной и должна быть, по его мнению, отвергнута $^{26}$. Однако задолго до работ Алексеева профрессор СанктПетербургской Духовной академии, выдающийся русский славист и библеист И. Е. Евсеев поставил дерзновенную задачу реконструировать текст первоначального перевода святителей Кирилла и Мефодия ${ }^{27}$. В 1915 году по его инициативе была создана Комиссия по научному изданию славянской Библии, в которую вошли все выдающие-

${ }^{26}$ См.: Алексеев А. А. Текстология славянской Библии. СПб., 1999 C. $219-220$.

${ }_{27}$ См.: Евсеев И. Е. Очерки по истории славянского перевода Биб лии. Пг., 1916; Он же. Геннадиевская Библия 1499. М., 1914; Он же. Столетняя годовщина русского перевода Библии. Пг, 1916. 
ся русские филологи того времени. Комиссия сочла, что для изучения и издания полного текста славянской Библии потребуется 60 лет. Нет никаких сомнений, не вмешайся в этот замысел роковые для России исторические события, эта задача была бы выполнена и мы сегодня имели бы совершенно другое направление в развитии нашей медиевистики, чем то, которое возобладало в советское время. Именно эта, уничтоженная, линия русской библеистики представляется нам более продуктивной, нежели та, которая ныне доминирует.

В частности, Евсеев, как и практически все русские исследователи того времени, вполне доверяли житию св. Кирилла, согласно которому, зернол переводческой работы славянского просветителя является Евангелие-апракос, начинающийся Евангелием от Иоанна: «...н тогда сложн пнсмена

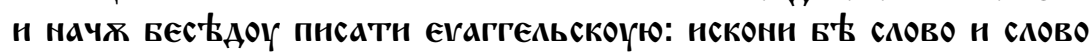
в' or вога н вогъ в' слово и прочжга». В таком случае именно пасхальное Евангелие от Иоанна, являющееся в славянской православной традиции не четвертылм, а первыли, и в целом Евангелие-апракос являются ядром русского евангельского текста. О важности именно такого вывода для доминантного вектора развития русской словесности мы уже писали ${ }^{28}$.

С точки же зрения Алексеева, хотя и «считается, что это сообщение Жития (процитированное нами выше. - И. E.) говорит о том, что переводческая работа Кирилла была начата с Евангелия-апракос... однако указание на краткий апракос нельзя считать вполне надежным», для него процитированные строки Жития «производят впечатление орнаментальной добавки» ${ }^{29}$. Для Алексеева неприемлем «апологетический тон в отношении переводов Кирилла и Мефодия» ${ }^{30}$, который он обнаруживает у Евсеева. Его оценку переводов славянских просветителей Алексеев называет «завышенной» ${ }^{31}$. В итоге текстологическую концепцию Евсеева, которая базируется именно на «националь-

\footnotetext{
${ }^{28}$ См.: Есаулов И. А. Пасхальность русской словесности. С. $10-43$.

${ }_{29}$ Алексеев А. А. Указ. соч. С. 145.

30 Там же. С. 165.

31 Там же. С. 219
}

ной Библии», «кирилло-мефодиевской Библии», Алексеев решительно отвергает.

Отрицая продуктивность идеи восстановления кирилломефодиевского текста, Алексеев настаивает на чрезвычайно узко понятом «историзме» как «продукте духовного развития XIX века» ${ }^{32}$, полагая при этом, что и Откровение подлежит ведению «обоснованного и последовательного историзма» ${ }^{33}$, однако не замечая анахронизма подобного понимания «историзма» для современной гуманитарной мысли. Несмотря на добротнейшее изучение им текстологии славянской Библии, позицию Алексеева, согласно предложенной выше типологии, можно отнести к еtic-подходу Нам же представляется, что етіс-подход, ясно проступающий в концепции полузабытого ныне Евсеева, хотя она и не была вполне развернута в свое время, все-таки является более перспективным для будущего русской фрилологии.

Евангельский текст, а также его производные, являются фундаментом русской культуры, если считать эту культуру христианской в своих основах. Уже много лет существует отдельное научное направление в этнографии, основателем которого является М. М. Громыко. Ее работы ${ }^{34}$ как и полевые исследования ее научной группы ${ }^{35}$, вполне доказали, что представления о «языческой сущности» русского народа, либо о его «двоеверии» в современной гуманитарной науке являются лишь чисто идеологическими спекуляциями тех, кто по разным причинам не может принять основополагающей значимости православной веры для русской культуры в целом.

Очень симптоматично, что в гуманитарном мире нынешней России ни етіс-подход, ни этнографические исследования группы Громыко (уже не говоря о концепции Евсеева) не получили такого научного резонанса, который они

32 Там же. С. 220.

33 Там же.

${ }^{34}$ Гролыко М. М. Мир русской деревни. М., 1991; Гролыкко М. М. Буганов А. В. О воззрениях русского народа. М., 2000.

${ }^{35}$ См. многотомное издание: Русские: народная культура (История и современность). М., 1995-2000, а также продолжающий выходить научный журнал: Традиции и современность. 2005- 
заслуживают. Представляется, однако, что эти и подобные этим гуманитарные направления могут быть научным подспорьем и для наших филологических исследований, для исследований тех, для которых евангельский текст не сводится лишь к набору цитат, а является фрундаментом русской литературы, русской культуры и самого бытия России. 